\title{
Identification and Characterization of In planta-Expressed Secreted Effector Proteins from Magnaporthe oryzae That Induce Cell Death in Rice
}

\author{
Songbiao Chen, ${ }^{1,2,3}$ Pattavipha Songkumarn, ${ }^{2}$ R. C. Venu, ${ }^{2}$ Malali Gowda, ${ }^{2}$ Maria Bellizzi, ${ }^{2}$ Jinnan Hu, ${ }^{2}$ \\ Wende Liu, ${ }^{1}$ Daniel Ebbole, ${ }^{4}$ Blake Meyers, ${ }^{5}$ Thomas Mitchell, ${ }^{2}$ and Guo-Liang Wang ${ }^{1,2}$ \\ ${ }^{1}$ State Laboratory for Biology of Plant Diseases and Insect Pests, Institute of Plant Protection, Chinese Academy of \\ Agricultural Sciences, Beijing 100193, China; ${ }^{2}$ Department of Plant Pathology, The Ohio State University, Columbus, OH \\ 43210, U.S.A.; ${ }^{3}$ Biotechnology Research Institute, Fujian Academy of Agricultural Sciences, Fuzhou, Fujian 350003, China; \\ ${ }^{4}$ Department of Plant Pathology and Microbiology, Texas A\&M University, College Station, TX 79016, U.S.A.; ${ }^{5}$ Delaware \\ Biotechnology Institute, University of Delaware, Newark, DE, U.S.A.
}

Submitted 16 May 2012. Accepted 24 September 2012.

Interactions between rice and Magnaporthe oryzae involve the recognition of cellular components and the exchange of complex molecular signals from both partners. How these interactions occur in rice cells is still elusive. We employed robust-long serial analysis of gene expression, massively parallel signature sequencing, and sequencing by synthesis to examine transcriptome profiles of infected rice leaves. A total of 6,413 in planta-expressed fungal genes, including 851 genes encoding predicted effector proteins, were identified. We used a protoplast transient expression system to assess 42 of the predicted effector proteins for the ability to induce plant cell death. Ectopic expression assays identified five novel effectors that induced host cell death only when they contained the signal peptide for secretion to the extracellular space. Four of them induced cell death in Nicotiana benthamiana. Although the five effectors are highly diverse in their sequences, the physiological basis of cell death induced by each was similar. This study demonstrates that our integrative genomic approach is effective for the identification of in planta-expressed cell death-inducing effectors from $M$. oryzae that may play an important role facilitating colonization and fungal growth during infection.

Coevolution of plants and their pathogens in nature has led both sides to develop a battery of strategies to attack and defend. Plant pathogens may first use cell wall-degrading enzymes to digest the surface layers of cell walls to facilitate penetration. Successful pathogens can secrete a variety of extracellular molecules to modulate host defense circuitry. These extracellular molecules include apoplastic effectors such as virulence factors, toxins, and degradative enzymes that function as key virulence determinants to suppress host defense (Hogenhout et

S. Chen, P. Songkumarn, and R. C. Venu contributed equally to this work.

Corresponding author: Guo-Liang Wang; Department of Plant Pathology; Ohio State University; Telephone: +1.614.292.9280; Fax: +1.614.292.4455; E-mail: wang.620@osu.edu

* The $e$-Xtra logo stands for "electronic extra" and indicates three supplementary tables, two supplementary figures, and supplementary methods information are published online.

(C) 2013 The American Phytopathological Society al. 2009). On the other hand, plants have evolved unique mechanisms to defend themselves from most microbes using physical barriers, antimicrobial compounds, and the innate immune system. The plant immune system consists of two layers (Chisholm et al. 2006; Jones and Dangl 2006). The first layer is initiated by the perception of pathogen- or microbe-associated molecular patterns (PAMPs or MAMPs) by host membrane-associated pattern recognition receptors (PRR), which cause basal defense responses in plants, called PAMP-triggered immunity (Zhang and Zhou 2010). The second layer is initiated by rapid activation of a hypersensitive reaction (HR) upon recognition of the avirulence effectors by the cognate resistance $(\mathrm{R})$ proteins, which causes strong race-specific resistance called effector-triggered immunity.

Over the past decade, extensive studies have led to the identification of many PAMP and avirulence effectors in plant pathogens and PRR and $\mathrm{R}$ proteins in plants (Dodds et al. 2009). Among them the majority of the well-characterized effectors are from prokaryotic bacteria that employ a type III secretion system to deliver effectors directly into host cells. Unlike bacteria, fungal and oomycete pathogens often secrete effector proteins to the extracellular milieu through the eukaryotic secretory pathway (Panstruga and Dodds 2009). Many secreted proteins function in the apoplast of plants, and some have been shown to be translocated into plant cells (Dou et al. 2008a; Whisson et al. 2007), in which they function in the host cytoplasm (Armstrong et al. 2005; Bos et al. 2006; Catanzariti et al. 2006; Dodds et al. 2004; Rehmany et al. 2005; Yoshida et al. 2009). Recent advances in genome sequencing technologies have led to a rapid discovery of numerous effectors in oomycete pathogens and have provided a wealth of information on their structure and function. For example, analysis of the Phytophthora sojae and $P$. ramorum genomes led to the discovery of conserved motifs RXLR and dEER (Tyler et al. 2006), required for the translocation of oomycete effectors into plant cells (Dou et al. 2008a; Whisson et al. 2007). The large family of predicted RXLR proteins thus provided a wealth of candidates for functional studies of effector activities in oomycetes. However, secreted proteins exported by fungi appear to lack such conserved motifs, and little is known about their functions.

The hemibiotrophic fungus Magnaporthe oryzae is the causal agent of rice blast, the most devastating disease that affects rice production worldwide (Dean et al. 2005; Ebbole 2007; Talbot 2003). In M. oryzae, a larger number of genes (up to 
1,306) coding for putative secreted proteins have been predicted from the genome of a laboratory strain, 70-15 (Dean et al. 2005; Yoshida et al. 2009). Seven secreted proteins, i.e., PWL1, PWL2 (Kang et al. 1995; Sweigard et al. 1995), AvrPita (Orbach et al. 2000), Avr-Pia, Avr-Pii, Avr-Pik/km/kp (Yoshida et al. 2009), and AvrPiz-t (Li et al. 2009), have been confirmed as avirulence (Avr) proteins presumably recognized by the corresponding resistance gene products. In addition, a few secreted proteins that are required for pathogenicity, i.e., MPG1 (Talbot et al. 1993), EMP1 (Ahn et al. 2004), MHP1 (Kim et al. 2005), MSP1 (Jeong et al. 2007), MC69 (Saitoh et al. 2012), and Slp1 (Mentlak et al. 2012), and four biotrophyassociated secreted proteins, BAS1 to BAS4 (Mosquera et al. 2009), have also been characterized. However, the majority of $M$. oryzae secreted proteins have not been experimentally tested for their functions in pathogenicity.

To identify $M$. oryzae genes encoding predicted secreted proteins that were expressed in blast-infected leaf tissue, we developed an integrative genome expression profiling approach that includes robust-long serial analysis of gene expression (RL-SAGE) (Gowda et al. 2004), massively parallel signature sequencing (MPSS) (Brenner et al. 2000; Meyers et al. 2004; Nobuta et al. 2007), and sequencing by synthesis (SBS) (German et al. 2008; Venu et al. 2011a). Infected tissues were collected from six timepoints so that fungal transcripts expressed in planta at a late infection stage can be included in the libraries. We used a protoplast transient expression assay to identify in planta-expressed secreted proteins from $M$. oryzae that induce cell death in rice. Among 42 tested proteins, five cell death-inducing proteins were functionally characterized. The integrative approach described here provides an efficient strategy for functional identification of fungal cell death-inducing proteins that are involved in plant and fungal interactions.

\section{RESULTS}

\section{Gene expression profiling in blast-infected rice leaves.}

To obtain more comprehensive gene expression profiles of $M$. oryzae during compatible and incompatible interactions with rice, we constructed one RL-SAGE, eleven MPSS, and seven SBS libraries for deep sequencing. The RL-SAGE library was generated from rice (cv. Nipponbare) leaves inoculated with the compatible isolate Che86061 at $96 \mathrm{~h}$ postinoculation (hpi) (Fig. 1A). A total of 18,154 significant signatures were obtained from the library. Among them, 3,105 (17.1\%) and 12,263 (67.5\%) significant signatures matched to the $M$. oryzae and rice genomes, respectively. The unmatched signatures may be due to sequencing errors or are located in the sequencing gaps in both the genomes. Only 14 signatures matched to both the M. oryzae and rice genomes, signifying that the majority of signatures were genome specific. We identified 3,091 signatures specifically matching to the $M$. oryzae genome, which correspond to 3,000 previously annotated $M$. oryzae genes.

Eleven MPSS libraries were generated from the leaves of wild-type Nipponbare plants or transgenic Nipponbare plants carrying the blast resistance gene $P i 9$ (Qu et al. 2006), which were inoculated with $M$. oryzae isolate $\mathrm{KJ} 201$ during the compatible $(3,6,12,24,48$, and $96 \mathrm{hpi})$ or incompatible interactions $(3,6,12,24$, and 48 hpi) (Fig. 1A). As expected, more signatures matched to the $M$. oryzae genome in the compatible interactions compared with that in the incompatible interactions. A total of 57,671 significant signatures were obtained from the five incompatible interaction MPSS libraries. Among these, $724(1.2 \%)$ and 38,024 (65.9\%) significant signatures uniquely matched to the $M$. oryzae and rice genomes, respectively. From the six compatible interaction libraries, a total of 63,132 significant signatures were obtained. Among them,
2,545 (4\%) and 41,784 (66.1\%) significant signatures uniquely matched to the $M$. oryzae and rice genomes, respectively. Altogether, 3,216 annotated $M$. oryzae genes were identified from both the compatible and incompatible MPSS libraries.

The same leaf tissue used for the generation of the MPSS libraries (the compatible interaction at 6, 12, 24, and 96 hpi and the incompatible interaction at 6,12 , and $24 \mathrm{hpi}$ ) were used for the construction of the seven SBS libraries (Fig. 1A). A total of 65,299 significant signatures were obtained from the three incompatible-interaction SBS libraries. Among them, 3,492 $(5.3 \%)$ and $49,706(76.1 \%)$ significant signatures specifically matched to the $M$. oryzae genome and rice genome, respectively. A total of 68,825 significant signatures were obtained from the four compatible-interaction SBS libraries. Signatures matching to the $M$. oryzae genome numbered 5,283 $(7.7 \%)$ and those matching to the rice genome numbered 50,756 (73.7\%). The SBS signatures from both compatible and incompatible interactions together identified 4,781 annotated $M$. oryzae genes. Altogether, a total of 6,413 annotated $M$. oryzae genes expressed during infection process were identified using the three expression profiling technologies (Fig. 1A).

\section{Identification of genes encoding putative secreted proteins expressed during infection.}

Secreted proteins are known to play essential roles during fungal-plant interactions (Rep 2005; Zhang and Zhou 2010). Thus, we focused on the analysis of the secreted protein genes that were identified in the transcriptome libraries described above. To obtain most putative secreted protein genes from the in planta-expressed gene collections, we used two M. oryzae secreted protein datasets, one by Dean and associates (2005) (referred to as dataset I) and the other by Choi and associates (2010) (referred to as dataset II) as references for manual annotation. A total of 851 distinct secreted protein genes were identified from both datasets (Fig. 1A, Supplementary Table S1). About $85.7 \%(264 / 308)$ of the putative secreted protein genes identified in dataset I were present in dataset II (Fig. 1E). Among the three RL-SAGE, MPSS, and SBS libraries made from the rice leaves inoculated with compatible isolates at the same timepoint (96 hpi) (RL-SAGE-96 h, MPSS-96 h, and SBS-96 h), over two times more secreted protein genes were identified from the SBS-96 h library than from the other two libraries in both datasets I and II (Fig. 1C and D).

To gain more insight on the function of in planta-expressed secreted proteins involved in the rice- $M$. oryzae interaction, we conducted a gene ontology (GO)-based classification. This analysis revealed that most in planta-expressed secreted proteins are associated with metabolic process, followed by developmental process, cellular process, and multicellular organismal process (Fig. 2A). For molecular functions, most in plantaexpressed secreted proteins are associated with catalytic activity and binding (Fig. 2B).

\section{Transient expression assays identified five $M$. oryzae apoplastic effectors that induce cell death in rice cells.}

Host cell death is a ubiquitous feature in plant-pathogen interactions. To identify $M$. oryzae secreted proteins involved in host cell death, we performed transient expression of $M$. oryzae secreted proteins in rice protoplasts, using our established method (Chen et al. 2006). In the assay, cell death is monitored by the reduced expression level of a cotransfected $\beta$-glucuronidase (GUS) reporter gene in rice protoplasts (Fig. 3A) (Dou et al. 2008b; Jia et al. 2000; Mindrinos et al. 1994; Yoshida et al. 2009). A total of 42 secreted protein genes were cloned for the transient expression assay (Supplementary Table S2). For each of the selected genes, two versions of transfection plasmids were constructed, one containing the full-length 
open reading frame (ORF) (referred to as FL) and the other containing the truncated coding region without the signal peptide sequence but with an engineered ATG start codon (referred to as NS). The transient assay revealed that five out of 42 secreted protein genes of the FL version caused a significant reduction in GUS activity when expressed in rice protoplasts (Fig. 3B), suggesting that these five proteins can induce cell death in rice cells. On the other hand, transient expression of all 42 examined genes of the NS version did not result in any reduction in cell viability. We thus referred to the five secreted proteins, MGG_03356, MGG_05531, MGG_07986, MGG_ 08409, and, MGG_10234, as MoCDIP1 to MoCDIP5 (M. oryzae cell death-inducing proteins), respectively.

We further performed Agrobacterium-mediated transformation of rice calli with binary vectors containing the five $M o C D I P$ genes to see whether it was possible to obtain stable transgenic lines with the expression of these genes for functional analysis. About 600 calli were used for the transformation of each construct. As expected, no resistant transgenic calli were obtained after transforming with FL-MoCDIP1, FL-MoCDIP2, FL$M o C D I P 3$, or $F L-M o C D I P 4$, individually (data not shown). By contrast, around 50 to 80 transgenic calli were obtained from the transformations with $N S-M o C D I P 1$, NS-MoCDIP2, $N S-M o C D I P 3$, or NS-MoCDIP4, with efficiencies similar to normal transformation efficiencies (around 8 to $15 \%$ for other constructs) in our lab. Interestingly, transformation with $F L$ MoCDIP5 at first yielded a normal efficiency of about 40 transgenic calli with no cell-death phenotypes. However, when they were cultured on the selection medium for 2 weeks or longer, the transgenic calli expressing FL-MoCDIP5 started to show cell-death phenotypes (Fig. 3C). Similar to other NS$M o C D I P$, no cell death was observed in the transgenic calli

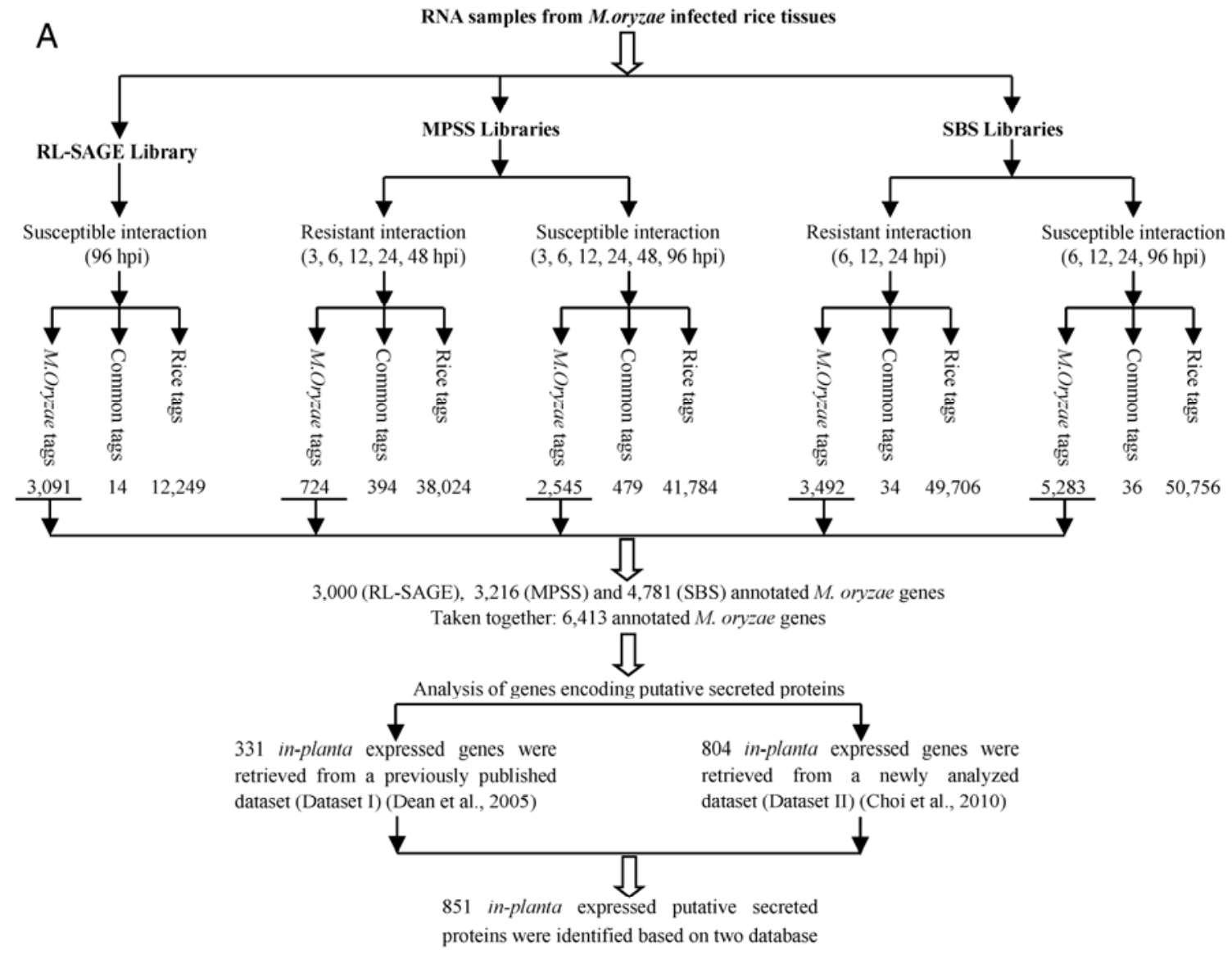

B

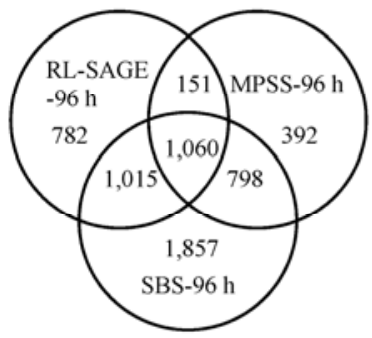

C

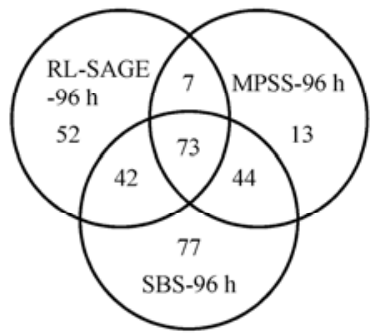

$\mathrm{D}$

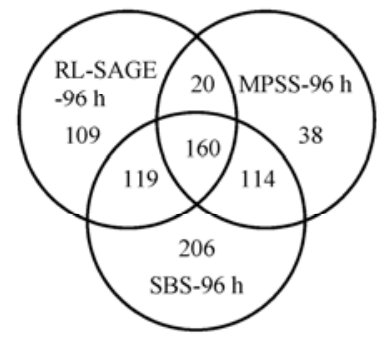

E

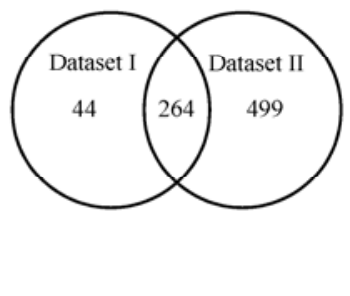

Fig. 1. Gene expression profiling of Magnaporthe oryzae during its interaction with rice. A, Summary statistics for gene expression profiling by robust-long serial analysis of gene expression (RL-SAGE), massively parallel signature sequencing (MPSS), and sequencing by synthesis (SBS), and identification of in planta-expressed M. oryzae genes encoding putative secreted proteins. B, Clustering analysis of all M. oryzae genes identified in the libraries of RL-SAGE$96 \mathrm{~h}$, MPSS-96 h, and SBS-96 h, respectively. C, Clustering analysis of putative M. oryzae secreted protein genes retrieved from dataset I (Dean et al. 2005) in RL-SAGE-96 h, MPSS-96 h, and SBS-96 h, respectively. D, Clustering analysis of putative M. oryzae secreted protein genes retrieved from dataset II (Choi et al. 2010) in RL-SAGE-96 h, MPSS-96 h, and SBS-96 h, respectively. E, Clustering analysis of putative M. oryzae secreted protein genes in all timepoints libraries retrieved from datasets I and II, respectively. 
expressing NS-MoCDIP5 (Fig. 3C). These results, consistent with the transient expression assay in rice protoplasts, confirmed that the five MoCDIP induced cell death when the fulllength proteins are expressed in rice cells.

\section{A}

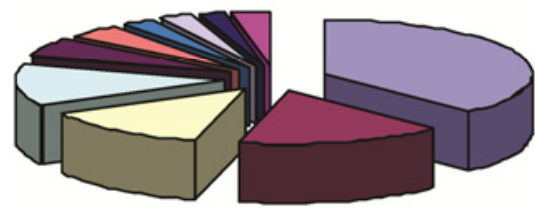

$\mathrm{B}$

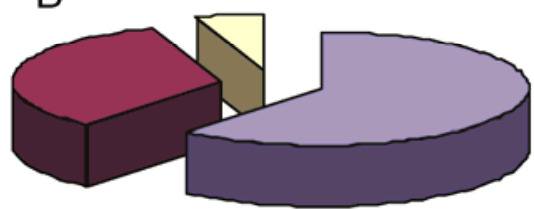

To functionally investigate the predicted secretion feature of the five identified MoCDIP, a yeast secretion assay was performed, following the method previously published (Lee et al. 2006). The sequences of both FL-MoCDIP and NS-MoCDIP

metabolic process, $38 \%$

$\square$ developmental process, $16 \%$

$\square$ cellular process, $13 \%$

$\square$ multicellular organismal process, $13 \%$

$\square$ multi-organism process, $6 \%$

$\square$ response to stimulus, $4 \%$

$\square$ cell wall organization or biogenesis, $3 \%$

$\square$ biological regulation, $2 \%$

localization, $2 \%$

$\square$ others, $3 \%$

$\square$ catalytic activity, $61 \%$

$\square$ binding, $34 \%$

$\square$ others, $5 \%$

Fig. 2. Gene ontology (GO) annotation of in planta-expressed Magnaporthe oryzae putative secreted proteins. A, Classification based on biological process. B, Classification based on molecular function.
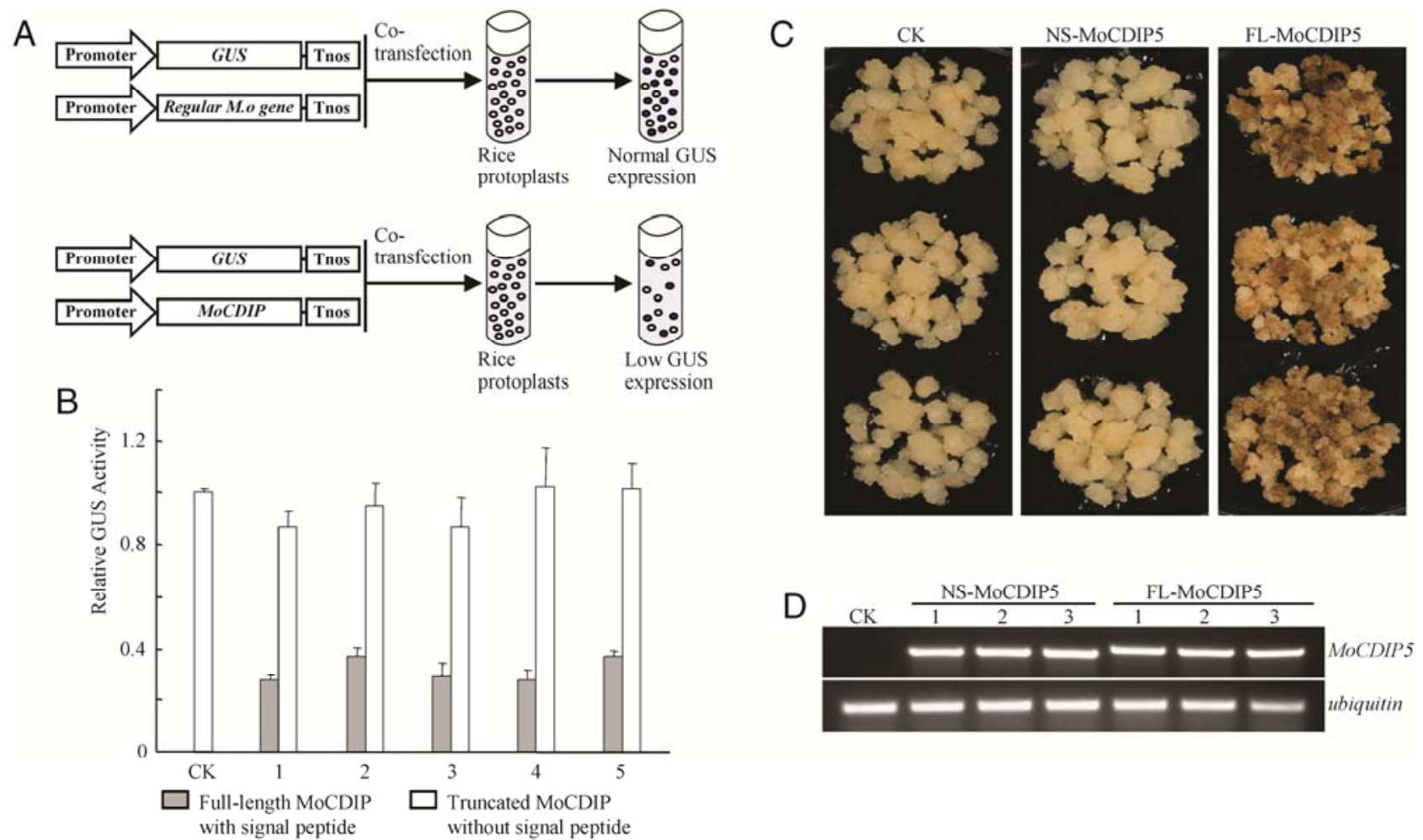

Fig. 3. Identification of five in planta-expressed putative secreted proteins that induce cell death in rice cells. A, Schematic representation of the rice protoplast transient expression assay approach to the identification of Magnaporthe oryzae secreted proteins that can induce rice cell death. Rice protoplasts were cotransfected with a reporter $\beta$-glucuronidase (GUS) construct (Promoter-GUS-Tnos) and the other construct (Promoter-M.o gene-Tnos) carrying a M. ory$z a e$ secreted protein gene. Rice cell viability was detected based on monitoring the reduced GUS expression level. MoCDIP = M. oryzae cell death inducing protein. B, Ectopic expression of the full length of five MoCDIP in rice protoplasts resulted in reduction in cell viability. CK = protoplast sample cotransfected with a GUS reporter and an empty vector control; 1 to $5=$ protoplast samples cotransfected with a GUS reporter and the other construct carrying MoCDIP1 to MoCDIP5, respectively. Data bars show averages from three triplicate samples in one experiment. Each experiment was repeated at least three times with similar results. C, Ectopic expression of a full-length but not truncated non-signal peptide version of MoCDIP5 resulted in cell death in transgenic rice calli. CK = rice calli transformed with empty vector; NS-MoCDIP5 =rice calli transformed with construct carrying a truncated non-signal peptide version of MoCDIP5; FL-MoCDIP5 = rice calli transformed with construct carrying a truncated full-length MoCDIP5. Pictures were taken at about 20 days when the newly obtained transgenic calli were maintained on selection media. Transformation experiments were repeated two times, and similar results were observed. D, Reverse transcription-polymerase chain reaction (RT-PCR) analysis of expression of NS-MoCDIP5 or FL-MoCDIP5 in transgenic rice calli. $\mathrm{CK}=\mathrm{RT}$-PCR result from the rice calli transformed with the empty vector control; 1 to $3=\mathrm{RT}$-PCR result from three independent transgenic calli lines. 
were fused in frame to the $\mathrm{N}$-terminal end of a yeast invertase gene (suc2) lacking its own signal peptide sequence. The fusion constructs were transformed into the yeast strain DBY $\alpha 2445$, an invertase-deficient mutant (Lee et al. 2006), and the transformed yeasts were grown directly on sucrose medium and were assayed for secretion. As expected, the yeast strain transformed with the constructs containing the NS-MoCDIP-suc2 fusions did not grow on sucrose medium (Supplementary Fig. $\mathrm{S} 1$ ), due to the lack of secreted invertase to catalyze the decomposition of sucrose into fructose and glucose as the carbon source. In contrast, all five constructs containing the fusions of the $F L-M o C D I P$-suc2 enabled the yeast mutant strain to grow on sucrose medium, confirming that the predicted signal peptides of the five MoCDIP are functional to direct the invertase fusions to the secretory pathway. These results, together with the results showing that the signal peptide is required for MoCDIP expressed in rice cells to induce rice cell death, indicate that these proteins most likely function in the plant apoplastic space. However, the exact target site of these proteins in plant cells remains to be elucidated.

\section{MoCDIP genes are expressed}

in infected leaves and appressoria.

To experimentally confirm that the MoCDIP genes are expressed in infected leaves and to determine their expression pattern in appressoria and mycelia, reverse transcription-polymerase chain reaction (RT-PCR) was carried out using the RNA extracted from Nipponbare rice leaves inoculated with the compatible blast isolate KJ201 and from M. oryzae appressoria and mycelia. Because of the low proportion of the fungal mass in the infected leaves at early infection stages, the Mo28S transcript was not detected before $72 \mathrm{hpi}$. Similar to the Mo28S transcript, the MoCDIP2 and MoCDIP4 transcripts were detected from the infected rice leaves only at $72 \mathrm{hpi}$, and the transcripts of MoCDIP1, MoCDIP3, and MoCDIP5 were detected from the infected rice leaves at 96 hpi (Fig. 4). This result confirmed that all five MoCDIP were expressed during infection stages. The transcripts of MoCDIP1 and MoCDIP2 were detected in both appressoria and mycelia with relatively higher expression in the former, and the transcripts of MoCDIP3, MoCDIP4, and MoCDIP5 were detected only in appressoria (Fig. 4).

\section{MoCDIP induce cell death in nonhost plant cells.}

Many pathogen effectors induce cell death in nonhost plant cells (Rep 2005). To determine whether the five MoCDIP have cell death effects in nonhost plant cells, we performed transient expression assays of the MoCDIP genes in the protoplasts of three model plants, maize (Zea mays), Arabidopsis thaliana, and Nicotianna benthamiana. Consistent with the results observed in rice protoplasts, transient expression of the five $F L$ $M o C D I P$ but not the NS-MoCDIP induced a significant reduction in cell viability in maize protoplasts (Fig. 5A). As for transient assays in protoplasts of dicot plants Arabidopsis and $N$. benthamiana, expression of the $F L-M o C D I P$, except for $F L$ $M o C D I P 2$, caused significant cell-viability reduction. Similar to the result in rice cells, expression of all five $N S-M o C D I P$ did not reduce cell viability in either Arabidopsis or N. benthamiana protoplasts (Fig. 5B and C).

We further tested the five MoCDIP in N. benthamiana leaves via an Agrobacterium-mediated transient-expression approach. A. tumefaciens containing the empty vector pGD and a pGD recombinant expressing WtsE were used as negative and positive controls, respectively. WtsE is a bacterial type III effector that induces cell death in both host and nonhost plants (Ham et al. 2008). Consistent with results from the protoplast assays, infiltration of $N$. benthamiana leaves with the
Agrobacterium strains expressing FL-MoCDIP1, FL$M o C D I P 3, F L-M o C D I P 4$, or FL-MoCDIP5 resulted in celldeath responses (Fig. 5D). On the contrary, infiltration of the $F L-M o C D I P 2$ strain, as well as infiltration of the strains carrying the constructs expressing the NS-MoCDIP, did not result in cell death in the infiltrated area. RT-PCR analysis was performed to examine the transient expression of the MoCDIP genes, and the results showed that both the FL-MoCDIP and $N S-M o C D I P$ genes were expressed at similar levels in the infiltrated $N$. benthamiana leaves (Fig. 5E). These results confirmed that MoCDIP1, MoCDIP3, MoCDIP4, and MoCDIP5, but not MoCDIP2 induce cell death in both monocot and dicot species.

The timing and appearance of the cell death in $N$. benthamiana leaves induced by the $F L-M o C D I P$ strains were not as strong as that induced by the WtsE strain. The cell death symptom induced by the WtsE strain usually started at 36 to $48 \mathrm{~h}$ after agroinfiltration, and the symptoms induced by the $F L$ $M o C D I P 1, F L-M o C D I P 3$, and FL-MoCDIP4 strains generally appeared at 2 to 3 days after agroinfiltration, with a severe cell death around the infiltrated site. However, the symptoms induced by FL-MoCDIP5 generally were visible at 4 to 6 days after agroinfiltration, with weak necrotic spots in the infiltrated area. This result together with the observation of cell death only in relative long-term cultured rice calli expressing $F L$ $M o C D I P 5$ suggests that FL-MoCDIP5 induces weak cell death in a delayed pattern.

\section{Physiological basis of the MoCDIP-induced cell death.}

Previous studies have shown that plant cell death induced by some microbial toxins or effectors share some conserved mechanisms (Asai et al. 2000; Qutob et al. 2006). To further characterize the physiological properties of the cell death induced by the MoCDIP, we performed inhibition assays in rice protoplasts and $N$. benthamiana leaves. Two cell death-inducing proteins, i.e., WtsE and Bax, were also included in the assays as the controls.

Calcium signaling has been shown to play an important role in the cell death process (Boudsocq et al. 2010; Lecourieux et al. 2002). To determine whether calcium signaling is required for the MoCDIP-induced cell death, $\mathrm{LaCl}_{3}$, a calcium channel inhibitor, was applied in the inhibition assays. Application of $\mathrm{LaCl}_{3}$ blocked cell death induced by the transient expression of all $M o C D I P$, suggesting that the cell-death process mediated by these proteins is dependent on a calcium signaling pathway.

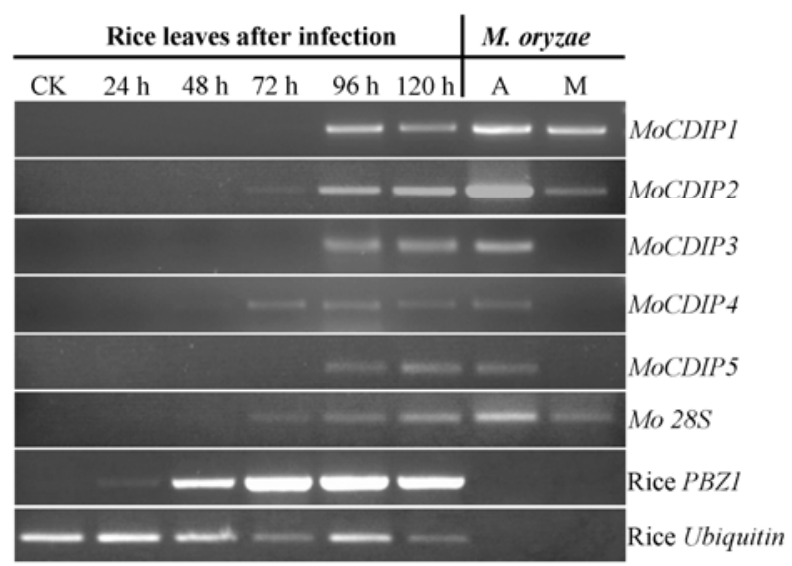

Fig. 4. In planta expression pattern of the five Magnaporthe oryzae cell death-inducing protein genes $(M o C D I P)$. Total RNA samples extracted from infected rice leaves $0,24,48,72,96$, or $120 \mathrm{~h}$ after inoculation, from in vitro-grown $M$. oryzae appresorium (A) and mycelium (M) were subjected to reverse transcription-polymerase chain reaction using specific primers. 
Light intensity has been demonstrated to be an important factor for cell-death induction triggered by some toxins or effectors (Asai et al. 2000; Qutob et al. 2006). To test whether MoCDIPinduced cell death is light-dependent, we transfected MoCDIP in rice protoplasts in the light or in the dark. There was no difference of cell viability between the protoplast samples incubated in either condition, indicating that the cell death process induced by the MoCDIP in rice protoplasts is light-independent (Table 1). In contrast, transient expression of the MoCDIP did not induce any cell-death lesions in the leaves of $N$. benthamiana kept in the dark (Table 1), suggesting that the MoCDIPinduced cell death in $N$. benthamiana leaves is light dependent.
Studies have shown that some antiapoptotic proteins such as BCL-2 family proteins and bax inhibitor-1 (BI-1) can suppress various types of cell death and are functionally conserved in yeast, plants, and mammals (Watanabe and Lam 2009). Overexpression of antiapoptotic proteins was shown to inhibit cell death induced by multiple stimuli, revealing that various types of cell death may have a common downstream mechanism (Dickman et al. 2001). We tested Bcl-xl, a member of the BCL-2 family, to determine whether MoCDIP-induced cell death can be inhibited by the antiapoptotic protein. Preinfiltration with $A$. tumefaciens cells harboring the $B c l$-xl expression vector did not produce cell-death symptoms after infiltration

Table 1. Inhibition assays of Magnaporthe oryzae cell death-inducing proteins in rice protoplasts and Nicotiana benthamiana leaves ${ }^{\mathrm{a}}$

\begin{tabular}{|c|c|c|c|c|c|c|c|c|c|c|}
\hline \multirow[b]{3}{*}{ Effector } & \multicolumn{10}{|c|}{ Applications or treatments } \\
\hline & \multicolumn{2}{|c|}{ Catalase } & \multicolumn{2}{|c|}{ DPI } & \multicolumn{2}{|c|}{$\mathrm{LaCl}_{3}{ }^{\mathrm{b}}$} & \multicolumn{2}{|c|}{ Dark } & \multicolumn{2}{|c|}{ Bcl_xl ${ }^{c}$} \\
\hline & $\mathbf{R P}$ & NBL & $\mathbf{R P}$ & NBL & $\mathbf{R P}$ & NBL & $\mathbf{R P}$ & NBL & $\mathbf{R P}$ & NBL \\
\hline MoCDIP1 & + & + & + & + & - & - & + & - & ND & - \\
\hline MoCDIP2 & - & ND & + & ND & - & ND & + & ND & ND & ND \\
\hline MoCDIP3 & + & + & + & + & - & - & + & - & ND & - \\
\hline MoCDIP4 & - & - & + & + & - & - & + & - & ND & - \\
\hline MoCDIP5 & - & - & + & + & - & - & + & - & ND & - \\
\hline WtsE & - & - & + & + & - & - & + & + & ND & - \\
\hline Bax & - & - & + & + & - & - & + & + & ND & - \\
\hline
\end{tabular}

${ }^{a} \mathrm{RP}=$ rice protoplasts, $\mathrm{NBL}=N$. benthamiana leaves, DPI $=$ diphenyleneiodonium sulfate, $+=$ cell death, $-=$ no cell death, and ND $=$ not determined.

${ }^{\mathrm{b}} \mathrm{LaCL}_{3}$ was dissolved in distilled water, and the same volume of water was applied to rice protoplasts or $N$. benthamiana leaves as control.

c An empty vector pGD was applied as control. No effects of controls on cell-death assays was observed.
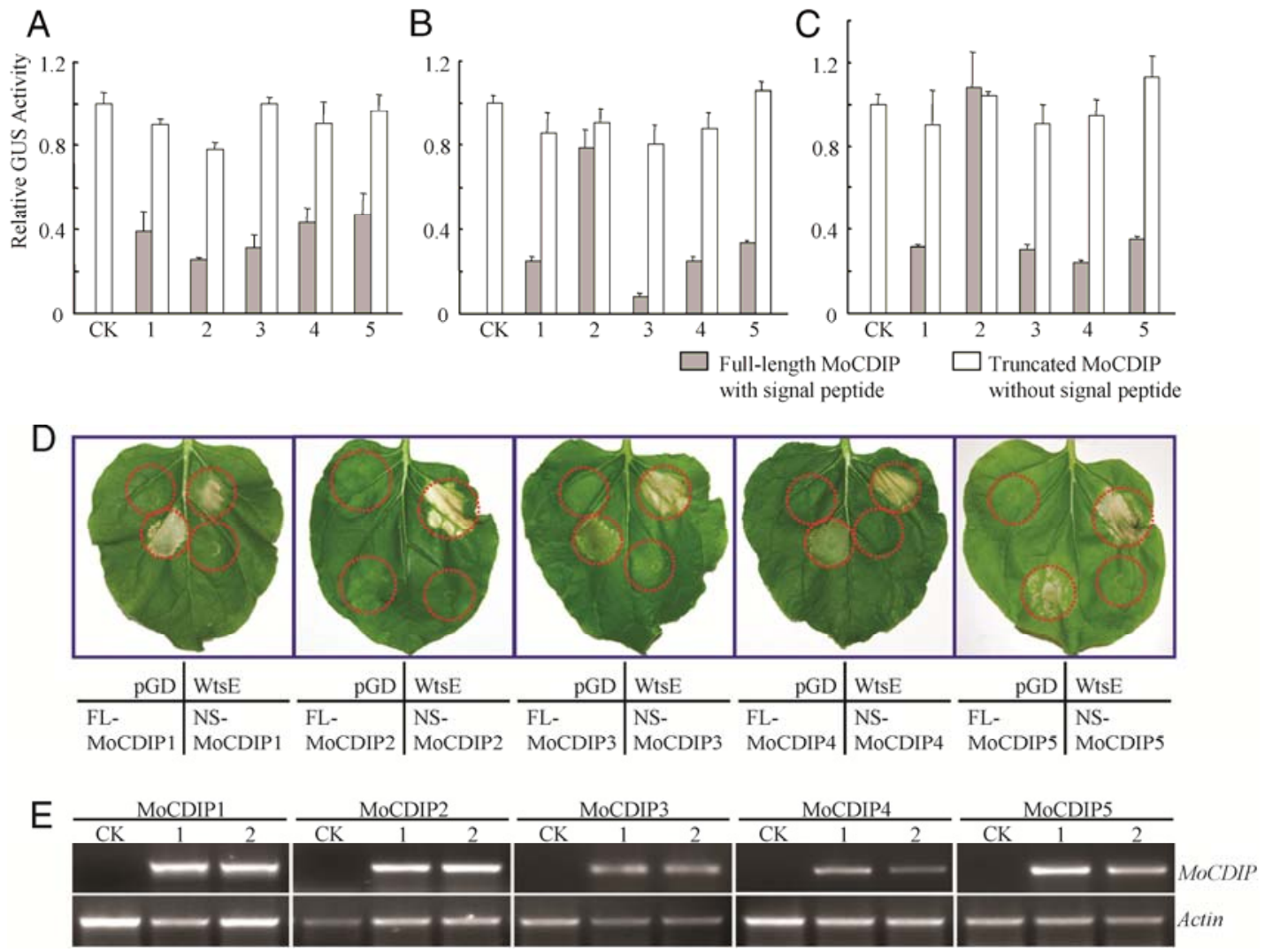

Fig. 5. Transient expression of the full-length but not truncated non-signal peptide version of Magnaporthe oryzae cell death inducing protein (MoCDIP) induced cell death in nonhost plant cells. A, B, and $\mathbf{C}$, Transient expression assay of the five MoCDIP in protoplasts of maize, Arabidopsis, and Nicotiana benthamiana, respectively. $\mathrm{CK}=$ protoplast sample cotransfected with a $\beta$-glucuronidase (GUS) reporter and an empty vector control; 1 to $5=$ protoplast samples cotransfected with a GUS reporter and the other construct carrying MoCDIP1to MoCDIP5, respectively. D, Transient expression assay of the five MoCDIP in N. benthamiana leaves by using an agroinfiltration approach. Agroinfiltration was performed on the same leaf side by side with Agrobacterium tumefaciens carrying an empty vector control $(p G D)$, a positive control (WtsE), constructs with full-length MoCDIP ( $F L$-MoCDIP), or constructs with non-signal peptide sequence MoCDIP (NS-MoCDIP), respectively. E, Reverse transcription-polymerase chain reaction (RT-PCR) analysis of MoCDIP expression in agroinfiltrated N. benthamiana leaves. Total RNA was extracted from $N$. benthamiana leaves at $36 \mathrm{~h}$ postinoculation. $\mathrm{CK}=\mathrm{RT}-\mathrm{PCR}$ result from tissues infiltrated with the empty vector control; 1 = RT-PCR result from tissues infiltrated with $F L-M o C D I P ; 2=$ RT-PCR result from tissues infiltrated with NS-MoCDIP. 


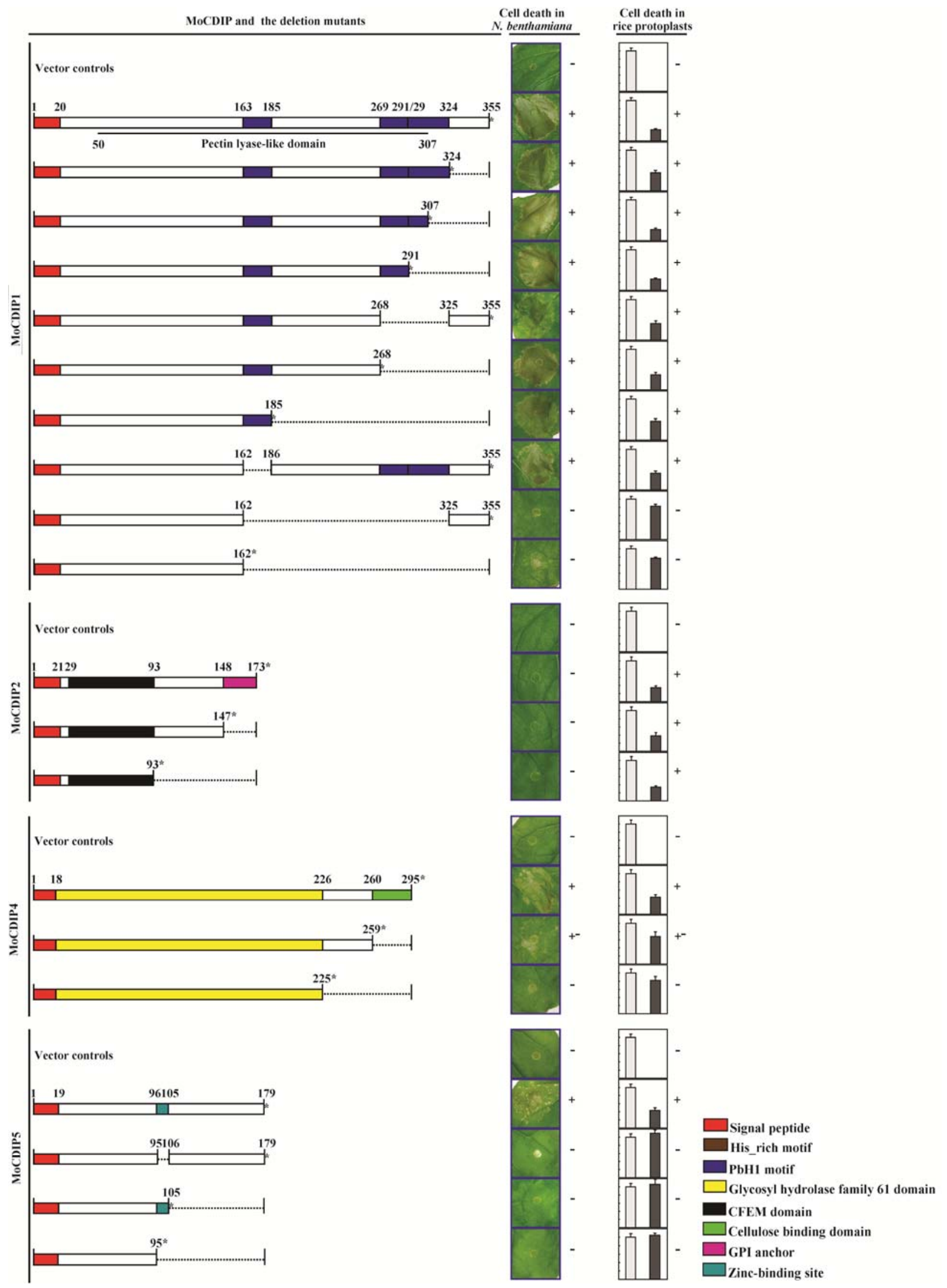

Fig. 6. Structural analyses of Magnaporthe oryzae cell death inducing proteins (MoCDIP). Schematic views of MoCDIP and their deletion mutants are shown on the left. The predicted domains or motifs of MoCDIP are represented as color rectangles. The deleted regions are represented as dotted lines. MoCDIP and their deletion mutants were transiently expressed in Nicotiana benthamiana leaves or rice protoplasts. Assay results from agroinfiltrated $N$. benthamiana leaves or transfected rice protoplasts are shown on the right. The signs $+_{,}+^{-}$, and - indicate obvious cell death, weak cell death, and no cell death, respectively. Data bars of protoplast results show averages from three triplicate samples in one experiment. Each experiment was repeated at least three times with similar results. 
with A. tumefaciens cells carrying MoCDIP, WtsE, or Bax. In contrast, $N$. benthamiana leaves preinfiltrated with the culture containing the empty vector showed obvious cell-death symptoms induced by the transient expression of MoCDIP, WtsE, or Bax. This result indicated that cell death in $N$. benthamiana leaves induced by MoCDIP is suppressed by the antiapoptotic protein (Table 1).

\section{Sequence and structural analysis of MoCDIP.}

Sequence analysis revealed that the five identified MoCDIP are highly diverse in their sequences and have no sequence homology with known cell death-inducing effectors in different pathogens, such as Nep1-like proteins (Qutob et al. 2006), INF1 (Kamoun et al. 1997), ToxA (Ciuffetti et al. 1997), ToxB (Martinez et al. 2001), or Nip (Mattinen et al. 2004). BLAST searches against the $M$. oryzae database and the NCBI nonredundant database revealed that MoCDIP2 and MoCDIP4 have a relatively large number of homologs in the sequenced genomes of $M$. oryzae and of other organisms (Supplementary Fig. S2). In contrast, MoCDIP1 and MoCDIP5 have homology to proteins only from other microorganisms (Supplementary Fig. S2), and MoCDIP3 has no homologs in the M. oryzae genome or in the sequenced genomes of other organisms. Homology searches also revealed that MoCDIP2 belonged to a family of CFEM-containing proteins that may function as a cell-surface receptor, signal transducers, or as adhesion molecules in host-fungi interactions (Kulkarni et al. 2003); MoCDIP4 was a highly conserved homolog to glycosyl hydrolase family 61 proteins (Davies and Henrissat 1995); and MoCDIP1 and MoCDIP5 shared similarity to ricin B lectin proteins, although there was no sequence similarity between the two proteins.

To further delineate the properties of the MoCDIP that are involved in cell-death induction, we searched conserved domains in the proteins and performed functional analysis of deletion mutants based on domain prediction. Deletion mutant constructs of $M o C D I P$, except for $M o C D I P 3$, because it does not contain any predicted domain, were tested in both rice protoplasts and N. benthamiana leaves (Fig. 6). Transient expression assays revealed that a MoCDIP1 mutant of the N-terminal region, amino acids (aa) 1 to 185 , was sufficient for inducing cell death in plant cells. However, the $\mathrm{N}$-terminal region, aa 1 to 162 , which lacks the $\mathrm{PbH} 1$ motif in the aa 1 to 185 fragment, lost the ability to induce cell death, suggesting that the $\mathrm{PbH} 1$ motif may play an important role in inducing cell death in plants. The N-terminal, CFEM domain-containing region of MoCDIP2 induced rice cell death efficiently, suggesting that the predicted GPI anchor was not required for cell-death induction. As for MoCDIP4, a deletion mutant lacking the cellulose binding domain (CBD) domain was found to induce only a weak cell death, and the mutant lacking both the linker fragment and the CBD domain failed to induce cell death, suggesting that the $\mathrm{C}$-terminus of the linker fragment and the CBD domain are functionally important in inducing cell death in plants. The assays also showed that MoCDIP5 mutants lacking the C-terminus or lacking the potential zinc-binding site motif failed to induce cell death in both rice protoplasts and $N$. benthamiana leaves, suggesting that the full length of MoCDIP5 is required for cell-death induction in plants.

\section{DISCUSSION}

\section{Transcriptome profiling in the rice-M. oryzae interaction.}

Using different gene-prediction algorithms, about $12 \%$ of the annotated genes $(1,546)$ are predicted to be putative effector proteins in the $M$. oryzae genome (Soanes et al. 2008). Whether these predicted genes are expressed in infected rice plants is largely unknown. By applying expressed sequence tag
(EST) analysis, RL-SAGE, and SuperSAGE analysis to infected rice leaves at the early infection stages, the defense transcriptome in response to $M$. oryzae infection was characterized (Ebbole et al. 2004; Gowda et al. 2007; Kim et al. 2001; Matsumura et al. 2003; Rauyaree et al. 2001). However, these studies only identified a small number of fungal genes, mainly because the proportion of the fungal RNA in the infected tissue was relatively low and the sequencing coverage was not deep enough. Recently, improved approaches for enrichment of fungal RNA from infected plant tissues have been employed to profile the interaction transcriptome of $M$. oryzae and rice. Kim and associates (2010) applied EST analysis coupled with subtractive hybridization of a cDNA library from infected leaves at very late stages of infection. A total of 712 uniEST were identified from the fungus, representing up to $31 \%$ of the total uniEST. Mosquera and associates (2009) developed a procedure to produce heavily infected rice sheaths that allowed isolation of total RNAs with a high proportion of RNA (up to $20 \%$ ) originating from biotrophic invasive hyphae of $M$. oryzae. By applying microarray analysis, the authors identified 262 fungal genes and 210 rice genes that were induced up to 10 fold during biotrophic invasion.

In this study, we employed three high-throughput technologies, i.e., RL-SAGE, MPSS, and SBS, to profile the transcriptome of $M$. oryzae-infected rice tissue. While RL-SAGE was only used to study gene-expression profiles from rice leaf tissue infected with a compatible isolate at $96 \mathrm{hpi}$, both MPSS and SBS were applied to study gene expression profiles of rice leaf tissue inoculated with either a compatible or incompatible isolate at different postinoculation timepoints. In the rice leaves at $72 \mathrm{hpi}$, inoculated with both incompatible and compatible isolates, only a very limited number of fungal genes were identified, as there were no visible symptoms or only a very few brown lesions appeared on the rice leaves. When inoculated with a compatible isolate at $96 \mathrm{hpi}$, rice leaves developed typical susceptible blast lesions. Consistently, a relatively large number of fungal transcripts were detected from heavily infected leaves. We identified 3,091 (17\%), 2,327 (12.3\%), and 5,099 (11.4\%) significant $M$. oryzae tags from the libraries of RL-SAGE-96 h, MPSS-96 h, and SBS-96 h, respectively. By combining results from three technologies, we identified a total of 6,413 M. oryzae genes, including 851 genes that are predicted to encode putative secreted proteins and might be expressed in planta. Our results together with those previously reported will provide valuable information for future studies of the molecular mechanisms underlying the rice- $M$. oryzae interaction.

Clustering analysis of the three 96-h libraries showed that the transcripts recovered from the RL-SAGE, MPSS, and SBS were partially overlapping, similar to previous results of transcriptional profiles of $M$. oryzae using MPSS, RL-SAGE, and oligoarray methods (Gowda et al. 2006). This result also suggests that using multiple different approaches can provide more comprehensive gene expression profiles. When considering individual technologies, SBS appeared to be the most efficient method for transcript profiling. While similar numbers of $M$. oryzae genes were identified from RL-SAGE-96 $\mathrm{h}$ and MPSS-96 h (3,008 and 2,401 unique $M$. oryzae genes from the two libraries, respectively), a total of 4,730 M. oryzae genes were identified from SBS-96 h (Fig. 1B), almost twice the gene numbers identified by the other two methods. Moreover, the $M$. oryzae transcripts recovered from SBS-96 h included most of the $M$. oryzae transcripts from RL-SAGE-96 $\mathrm{h}$ or MPSS-96 h. Our results indicated that many weakly expressed transcripts of both rice and $M$. oryzae were recovered in the libraries, due to the deep coverage of the transcriptome. As the sequencing cost is rapidly declining, the SBS-based ultra-fast sequencing method or other next-generation sequencing plat- 
forms will allow for more in-depth characterization of plantpathogen interaction transcriptomes.

Functional identification of $M$. oryzae effectors using the rice protoplast transient expression system.

Transcriptional analysis of the $M$. oryzae effector genes in infected rice plants has provided a starting point for functional analysis of the in planta-expressed genes in the rice-M. oryzae interaction. Over the past two decades, several $M$. oryzae avirulence or pathogenicity effector genes have been isolated by map-based cloning (Kang et al. 1995; Orbach et al. 2000; Sweigard et al. 1995), genetic association analysis (Yoshida et al. 2009), or loss-of-function (Ahn et al. 2004; Jeong et al. 2007; Kim et al. 2005; Talbot et al. 1993) approaches. The first two procedures are time-consuming, tedious, and expensive. As for loss-of-function approach, it is often hampered by the fact that many genes may have overlapping functions. For example, many knockout mutants of secreted protein genes have no identifiable phenotype (Mosquera et al. 2009). Thus, a costefficient and high-efficiency gain-of-function method would be a valuable alternative approach to the identification of $M$. oryzae effectors.

As for gain-of-function identification, the agroinfiltration transient assay is a widely used approach for characterizing function of phytopathogen effectors in many solanaceous plants, especially in N. benthamiana and N. tabacum (Munkvold and Martin 2009). However, this agroinfiltration method is not applicable in monocot plants. We previously reported a protoplast transient expression system to perform assays directly in rice cells (Chen et al. 2009a). Recently, Yoshida and associates (2009) and Okuyama and associates (2011) detected HR in rice protoplasts coexpressing $R$ gene and its cognate $A v r$ gene from $M$. oryzae. Using the system, they successfully screened the candidates of M. oryzae Avr-Pia, Avr-Pii, Avr-Pik/km/kp, and rice blast resistance gene $P i a$. In this study, we identified five $M$. oryzae effectors that induce cell death in rice cells. The results demonstrate that the rice protoplast expression assay is an efficient method for large-scale screening of putative effectors that induce cell death or HR reaction.

\section{Role of MoCDIP in the interaction between $M$. oryzae and rice.}

Unlike many bacterial pathogens that deliver effector proteins inside host cells via a type III secretion system, eukaryotic plant pathogens, like oomycetes and fungi, seem to secrete a large number of extracellular proteins via the eukaryotic (type II) secretory pathway (Panstruga and Dodds 2009). Some secreted proteins are translocated into host cells and function in the host cytoplasm to suppress host defenses. Many others function in the host apoplastic space to facilitate the parasitic lifestyle of pathogens. The latter include degradative enzymes, toxins, or inhibitors of plant enzymes. More recently, a broader definition of the term effector was suggested to include these secreted proteins, as they exert some effect on plant cells (Hogenhout et al. 2009). Over the past few decades, several apoplastic effectors with toxin or elicitor activity that can induce cell death in plants have been identified from eukaryotic plant pathogens (Rep 2005). Many of these apoplastic effectors play a positive role in the virulence of the hemibiotrophic or necrotrophic plant pathogens (Ottmann et al. 2009; Qutob et al. 2006). From 42 in planta-expressed M. oryzae putative secreted proteins, we successfully identified five novel effectors MoCDIP1 to MoCDIP5 that induce plant cell death. Given the fact that these genes are expressed during infection stages, especially 96 hpi (Fig. 4), we speculate that some of these cell death-inducing effectors may facilitate the colonization of $M$. oryzae during the late necrotrophic phase of the blast infection, which is a common mechanism among different pathosystems (Gijzen and Nurnberger 2006). It will be interesting to identify the receptor of these effectors in rice cells and define the interactions that trigger rice cell necrosis.

The five MoCDIP are highly diverse in their sequences. While MoCDIP3 does not share any significant similarity with any known proteins, MoCDIP1, MoCDIP2, MoCDIP4, and MoCDIP5 have closely related homologs from $M$. oryzae or other microorganisms. Our analysis also revealed that cell death induced by the five different MoCDIP share similar physiological phenotypes, such as the response to light, to inhibitors of calcium channel, and to Bcl-x1-mediated cell death suppression. These results together suggest that the cell death-inducing mechanism of the five MoCDIP might be similar, though their sequences are quite different. Among the five MoCDIP, MoCDIP4 belongs to a large family of cellulolytic enzymes from a wide variety of microorganisms. Related homologous proteins include endoglucanase, xylanase, and acetylxylan esterase. Several previous studies have observed that the expression of genes encoding members of this family of enzymes was modulated by mitogen-activated protein kinase signaling pathways, which play critical roles in regulating pathogenesis as well as other features (Lev and Horwitz 2003; Madhani et al. 1999; Roberts et al. 2000). However, because of redundancy among cellulolytic enzymes, knock-out of one or even several genes encoding cellulolytic enzymes had little or no consequences for virulence (Lev and Horwitz 2003). In this report, we demonstrate that MoCDIP4, a putative endoglucanase, induces cell death when it is expressed in plant cells. Hence, our finding provides a new clue to the mechanism by which the cellulolytic enzymes can aid invasion of microorganisms. MoCDIP4 contains two conserved domains, a glycosyl hydrolase family 61 domain and a fungal CBD. Recently, the fungal CBD have been shown to be important for the function of a Phytophthora elicitor lectin CBEL in plant cell-death induction (Gaulin et al. 2006) and for the function of a Trichoderma swollenin in plant root colonization (Brotman et al. 2008). More interestingly, the CBD domain was identified as a novel type of PAMP in microorganisms (Brotman et al. 2008; Gaulin et al. 2006). Consistent with previous reports, the CBD domain of MoCDIP4 was found to be important in inducing plant cell death (Fig. 6), strengthening the notion that the CBD plays a functionally conserved role, such as serving as a PAMP elicitor among different plant-pathosystems.

\section{MATERIALS AND METHODS}

\section{Plant materials and fungal strains.}

Rice (Oryza sativa) materials used in this study were wildtype Nipponbare plants and transgenic Nipponbare plants carrying a blast resistance gene $P i 9(\mathrm{Qu}$ et al. 2006). M. oryzae isolates used in this study include Che86061 and KJ201.

\section{Construction and data analyses \\ of RL-SAGE, MPSS, and SBS libraries.}

RNA samples isolated from rice leaves inoculated with $M$. oryzae isolates were used for library construction. The RLSAGE library was constructed following previously described procedures (Gowda et al. 2004). MPSS library construction was carried out at Illumina (San Diego, CA, U.S.A.), as described (Brenner et al. 2000; German et al. 2008; Meyers et al. 2004). The same total RNAs used for the MPSS library construction (except samples from leaves collected at 3 and 48 hpi) were used for the SBS library construction using our published protocols (Venu et al. 2011a).

RL-SAGE clones were sequenced at the Arizona Genome Institute (Tucson, AZ, U.S.A.). RL-SAGE signatures were 
identified using the SAGEspy program. MPSS tag processing was carried out at Illumina (Brenner et al. 2000; Meyers et al. 2004; Lu et al. 2005). The distinct RL-SAGE, MPSS, and SBS tag sequences were matched to the $M$. oryzae reference sequences, including the whole genomic sequences, annotated genes, and $500 \mathrm{bp}$ upstream (putative $5^{\prime}$ untranslated region [UTR]) and downstream (putative $3^{\prime}$ UTR) regions that are available from the Broad Institute (version 6.0) (Gowda et al. 2006; Venu et al. 2007; Venu et al. 2010, 2011a and b). Rice and $M$. oryzae transcript signatures from RL-SAGE, MPSS, and SBS experiments were separated after matching signatures to the whole genomic sequence of both rice (Michigan State University's Plant Biology directory) and M. oryzea. To identify in planta-expressed $M$. oryzae genes encoding for putative secreted proteins, the experimental RL-SAGE, MPSS, and SBS signatures were matched to two computational prediction datasets of $M$. oryzae secreted proteins (Choi et al. 2010; Dean et al. 2005). Clustering analysis using Microsoft access was performed to identify the putative secreted protein genes expressed specifically or commonly among the three platforms. The RL-SAGE data were deposited at the Magnaporthe oryzae community annotation database and the MPSS and SBS data were deposited at Arabidopsis MPSS Plus database.

\section{Cloning of $M$. oryzae genes encoding putative secreted protein and construction of $M o C D I P$-related vectors.}

We first selected about 100 putative secreted protein genes with high expression levels from the libraries. We had difficulty cloning some of the genes, mainly because the proportion of fungal RNA in the total RNA from infected rice leaves was relatively low. Some of the genes were cloned from $M$. oryzae EST clones or from $M$. oryzae genomic DNA, for those with no intron. A total of 42 in planta-expressed $M$. oryzae putative secreted protein genes were selected for functional characterization based on the profiling data. The genes were amplified by PCR, using specific primers, and were cloned into plant expression vector pXUN (Chen et al. 2009b). MoCDIPrelated vectors were generated based on fragments cloned into pXUN.

\section{Protoplast transient expression assays.}

Transient expression assays in the protoplasts of rice, maize, Arabidopsis, and N. benthamiana were carried out following previously described procedures (Chen et al. 2006; Sheen 2001). For transient assays in rice and maize cells, protoplasts were cotransfected with a maize ubiquitinl promoter-gus construct (Chen et al. 2006) and the pXUN-based construct of $M$. oryzae secreted protein genes, and for transient assays in Arabidopsis and $N$. benthamiana cells, protoplasts were cotransfected with a Cauliflower mosaic virus $35 \mathrm{~S}$ promoter-gus construct (Odell et al. 1985) and the pGD-based construct (Goodin et al. 2002) of $M$. oryzae secreted protein genes. After transfection, protoplasts were incubated at room temperature for 16 to $24 \mathrm{~h}$. GUS activity was detected essentially as described (Jefferson et al. 1987), using 4-methylumbelliferyl- $\beta$-D-glucuronide (Sigma-Aldrich, St Louis) as the substrate.

More details of materials and methods are available in the Supplementary Materials and Methods published online.

\section{ACKNOWLEDGMENTS}

We are grateful to M. M. Goodin, University of Kentucky, for kindly providing the pGDG and pGDR plasmids and B. Jaffee for editing the manuscript. This project is supported by the National Science FoundationPlant Genome Research Program (numbers 0605017 and 0701745), and by the National Natural Science Foundation of China (number 31171808). S. Chen, P. Songkumarn, and R. C. Venu were involved in the conception and planning of the study, carried out the experiments, and drafted the manuscript. M. Gowda, M. Bellizzi, J. Hu, and W. Liu were involved in performing part of experiments; D. Ebbole, B. C. Meyers, and T. Mitchell were involved in interpretation of results and writing the manuscript. G.-L. Wang was responsible for conception and planning of the study, interpretation of results, and writing the manuscript. All authors read and approved the final manuscript. The authors declare that they have no competing interests.

\section{LITERATURE CITED}

Ahn, N., Kim, S., Choi, W., Im, K. H., and Lee, Y. H. 2004. Extracellular matrix protein gene, EMP1, is required for appressorium formation and pathogenicity of the rice blast fungus, Magnaporthe grisea. Mol. Cells 17:166-173.

Armstrong, M. R., Whisson, S. C., Pritchard, L., Bos, J. I., Venter, E., Avrova, A. O., Rehmany, A. P., Böhme, U., Brooks, K., Cherevach, I., Hamlin, N.,White, B., Fraser, A., Lord, A., Quail, M, A., Churcher, C., Hall, N., Berriman, M., Huang, S., Kamoun, S., Beynon, J, L., and Birch, P. R. 2005. An ancestral oomycete locus contains late blight avirulence gene Avr3a, encoding a protein that is recognized in the host cytoplasm. Proc. Natl. Acad. Sci. U.S.A. 102:7766-7771.

Asai, T., Stone, J. M., Heard, J. E., Kovtun, Y., Yorgey, P., Sheen, J., and Ausubel, F. M. 2000. Fumonisin B1-induced cell death in Arabidopsis protoplasts requires jasmonate-, ethylene-, and salicylate-dependent signaling pathways. Plant Cell 12:1823-1836.

Bos, J. I., Kanneganti, T. D., Young, C., Cakir, C., Huitema, E., and Win, J., Armstrong, M. R., Birch, P. R., Kamoun, S. 2006. The C-terminal half of Phytophthora infestans RXLR effector AVR3a is sufficient to trigger R3a-mediated hypersensitivity and suppress INF1-induced cell death in Nicotiana benthamiana. Plant J. 48:165-176.

Boudsocq, M., Willmann, M. R., McCormack, M., Lee, H., Shan, L., He, P., Bush, J., Cheng, S. H., and Sheen, J. 2010. Differential innate immune signalling via $\mathrm{Ca}^{2+}$ sensor protein kinases. Nature 464:418-422.

Brenner, S., Johnson, M., Bridgham, J., Golda, G., Lloyd, D. H., Johnson, D., Luo, S., McCurdy, S., Foy, M., and Ewan, M. 2000. Gene expression analysis by massively parallel signature sequencing (MPSS) on microbead arrays. Nat. Biotechnol. 18:630-634.

Brotman, Y., Briff, E., Viterbo, A., and Chet, I. 2008. Role of swollenin, an expansin-like protein from Trichoderma, in plant root colonization. Plant Physiol. 147:779-789.

Catanzariti, A. M., Dodds, P. N., Lawrence, G. J., Ayliffe, M. A., and Ellis, J. G. 2006. Haustorially expressed secreted proteins from flax rust are highly enriched for avirulence elicitors. Plant Cell 18:243-256.

Chen, S., Tao, L., Zeng, L., Vega-Sanchez, M. E, Umemura, K., and Wang, G.-L. 2006. A highly efficient transient protoplast system for analyzing defence gene expression and protein-protein interactions in rice. Mol. Plant Pathol. 7:417-427.

Chen, S., Gowda, M., Venu, R. C., Songkumarn, P., Park, C. H., Bellizzi, M., Ebbole, D. J., and Wang, G.-L. 2009a. Isolation and functional analysis of putative effectors from Magnaporthe oryzae using integrated genomic approaches. Pages 93-103 in: Advances in Genetics, Genomics and Control of Rice Blast Disease, G.-L. Wang, B. Valent, eds. Springer, Dordrecht, The Netherlands.

Chen, S., Songkumarn, P., Liu, J., and Wang, G.-L. 2009b. A versatile zero background $\mathrm{T}$-vector system for gene cloning and functional genomics. Plant Physiol. 150:1111-1121.

Chisholm, S. T., Coaker, G., Day, B., and Staskawicz, B. J. 2006. Hostmicrobe interactions: Shaping the evolution of the plant immune response. Cell 124:803-814.

Choi, J., Park, J., Kim, D., Jung, K., Kang, S., and Lee, Y. H. 2010. Fungal secretome database: Integrated platform for annotation of fungal secretomes. BMC Genomics 11:105. doi:10.1186/1471-2164-11-105. Published online.

Ciuffetti, L. M., Tuori, R. P., and Gaventa, J. M. 1997. A single gene encodes a selective toxin causal to the development of tan spot of wheat. Plant Cell 9:135-144.

Davies, G., and Henrissat, B. 1995. Structures and mechanisms of glycosyl hydrolases. Structure 3:853-859.

Dean, R. A., Talbot, N. J., Ebbole, D. J., Farman, M. L., Mitchell, T. K., Orbach, M. J., Thon, M., Kulkarni, R., Xu, J. R., and Pan, H. 2005. The genome sequence of the rice blast fungus Magnaporthe grisea. Nature 434:980-986

Dickman, M. B., Park, Y. K., Oltersdorf, T., Li, W., Clemente, T., and French, R. 2001. Abrogation of disease development in plants expressing animal antiapoptotic genes. Proc. Natl. Acad. Sci. U.S.A. 98:6957-6962.

Dodds, P. N., Lawrence, G. J., Catanzariti, A. M., Ayliffe, M. A., and Ellis, J. G. 2004. The Melampsora lini AvrL567 avirulence genes are expressed in haustoria and their products are recognized inside plant cells. Plant Cell 16:755-768. 
Dodds, P. N., Rafiqi, M., Gan, P. H., Hardham, A. R., Jones, D. A., and Ellis, J. G. 2009. Effectors of biotrophic fungi and oomycetes: Pathogenicity factors and triggers of host resistance. New Phytol. 183:993-1000.

Dou, D., Kale, S. D, Wang, X., Jiang, R. H., Bruce, N. A., Arredondo, F. D., Zhang, X., and Tyler, B. M. 2008a. RXLR-mediated entry of Phytophthora sojae effector Avrlb into soybean cells does not require pathogen-encoded machinery. Plant Cell 20:1930-1947.

Dou, D., Kale, S. D., Wang, X., Chen, Y., Wang, Q., Wang, X., Jiang, R. H., Arredondo, F. D., Anderson, R. G., Thakur, P. B., McDowell, J. M. Wang, Y., and Tyler, B. M., 2008b. Conserved C-terminal motifs required for avirulence and suppression of cell death by Phytophthora sojae effector Avr1b. Plant Cell 20:1118-1133.

Ebbole, D. J. 2007. Magnaporthe as a model for understanding host-pathogen interactions. Ann. Rev. Phytopathol. 45:437-456.

Ebbole, D. J., Jin, Y., Thon, M., Pan, H., Bhattarai, E., Thomas, T., and Dean, R. 2004. Gene discovery and gene expression in the rice blast fungus, Magnaporthe grisea: Analysis of expressed sequence tags. Mol. Plant-Microbe Interact 17:1337-1347.

Gaulin, E., Dramé, N., Lafitte, C., Torto-Alalibo, T., Martinez, Y, AmelineTorregrosa, C., Khatib, M., Mazarguil, H., Villalba-Mateos, F., Kamoun,S., Mazars, C., Dumas, B., Bottin, A., Esquerre-Tugaye, M, T. and Rickauer, M. 2006. Cellulose binding domains of a Phytophthora cell wall protein are novel pathogen-associated molecular patterns. Plant Cell 18:1766-1777.

German, M. A., Pillay, M., Jeong, D. H., Hetawal, A., Luo, S., Janardhanan, P., Kannan, V., Rymarquis, L. A., Nobuta, K., German, R. De Paoli, E. Lu, C., Schroth, G., Meyers, B. C., and Green, P. J. 2008. Global identification of microRNA-target RNA pairs by parallel analysis of RNA ends. Nat. Biotechnol. 26:941-946.

Gijzen, M., and Nurnberger, T. 2006. Nep1-like proteins from plant pathogens: Recruitment and diversification of the NPP1 domain across taxa. Phytochemistry 67:1800-1807.

Goodin, M. M., Dietzgen, R. G., Schichnes, D., Ruzin, S., and Jackson, A O. 2002. pGD vectors: Versatile tools for the expression of green and red fluorescent protein fusions in agro-infiltrated plant leaves. Plant J. 31:375-383.

Gowda, M., Jantasuriyarat, C., Dean, R. A., and Wang, G-L. 2004. RobustLongSAGE (RL-SAGE): A substantially improved LongSAGE method for gene discovery and transcriptome analysis. Plant Physiol. 134:890897.

Gowda, M., Venu, R. C., Raghupathy, M. B., Nobuta, K., Li, H., Wing, R., Stahlberg, E., Couglan, S., Haudenschild, C. D., Dean, R., Nahm, B. H., Meyers, B. C., and Wang, G.-L., 2006. Deep and comparative analysis of the mycelium and appressorium transcriptomes of Magnaporthe grisea using MPSS, RL-SAGE, and oligoarray methods. BMC Genomics 7:310. doi:10.1186/1471-2164-7-310. Published online.

Gowda, M., Venu, R. C., Li, H., Jantasuriyarat, C., Chen, S., Bellizzi, M., Pampanwar, V., Kim, H., Dean, R. A., Stahlberg, E., Wing, R., Soderlund, C., and Wang, G.-L. 2007. Magnaporthe grisea infection triggers RNA variation and antisense transcript expression in rice. Plant Physiol. 144:524-533

Ham, J. H., Majerczak, D., Ewert, S., Sreerekha, M. V., Mackey, D., and Coplin, D. 2008. WtsE, an AvrE-family type III effector protein of Pantoea stewartii subsp. stewartii, causes cell death in non-host plants. Mol. Plant Pathol. 9:633-643.

Hogenhout, S. A., Van der Hoorn, R. A. L., Terauchi, R., and Kamoun, S. 2009. Emerging concepts in effector biology of plant-associated organisms. Mol. Plant-Microbe Interact. 22:115-122.

Jefferson, R. A., Kavanagh, T. A., and Bevan, M. W. 1987. GUS fusions: Beta-glucuronidase as a sensitive and versatile gene fusion marker in higher plants. EMBO (Eur. Mol. Biol. Organ.) J. 6:3901-3907.

Jeong, J. S., Mitchell, T. K., and Dean, R. A. 2007. The Magnaporthe grisea snodprot1 homolog, MSP1, is required for virulence. FEMS (Fed. Eur. Microbiol. Soc.) Lett. 273:157-165.

Jia, Y., McAdams, S. A., Bryan, G. T., Hershey, H. P., and Valent, B. 2000. Direct interaction of resistance gene and avirulence gene products confers rice blast resistance. EMBO (Eur. Mol. Biol. Organ.) J. 19:40044014

Jones, J. D., and Dangl, J. L. 2006. The plant immune system. Nature 444:323-329.

Kamoun, S., van West, P., de Jong, A. J, de Groot, K. E, Vleeshouwers, V. G. G. A., and Govers, F. 1997. A gene encoding a protein elicitor of Phytophthora infestans is down-regulated during infection of potato. Mol Plant-Microbe Interact. 10:13-20.

Kang, S., Sweigard, J. A, and Valent, B. 1995. The PWL host specificity gene family in the blast fungus Magnaporthe grisea. Mol. PlantMicrobe Interact. 8:939-948.

Kim, S., Ahn, I. P., and Lee, Y.-H. 2001. Analysis of genes expressed during rice-Magnaporthe grisea interactions. Mol. Plant-Microbe Interact. 14:1340-1346.
Kim, S., Ahn, I. P., Rho, H. S., and Lee, Y. H. 2005. MHP1, a Magna porthe grisea hydrophobin gene, is required for fungal development and plant colonization. Mol. Microbiol. 57:1224-1237.

Kim, S., Park, J., Park, S. Y., Mitchell, T. K., and Lee, Y. H. 2010. Identification and analysis of in-planta expressed genes of Magnaporthe oryzae. BMC Genomics 11:104. doi:10.1186/1471-2164-11-104. Published online.

Kulkarni, R. D., Kelkar, H. S., and Dean, R. A. 2003. An eight-cysteinecontaining CFEM domain unique to a group of fungal membrane proteins. Trends Biochem, Sci. 28:118-121.

Lecourieux, D., Mazars, C., Pauly, N., Ranjeva, R., and Pugin, A. 2002. Analysis and effects of cytosolic free calcium increases in response to elicitors in Nicotianna plumbaginifolia cells. Plant Cell 14:2627-2641.

Lee, S.-J., Kelley, B. S., Damasceno, C. M. D., St. John, B., Kim, B.-S., Kim, B.-D., and Rose, J. K. R. 2006. A functional screen to characterize the secretomes of eukaryotic pathogens and their hosts in-planta. Mol Plant-Microbe Interact. 19:1368-1377.

Lev, S., and Horwitz, B.A. 2003. A mitogen-activated protein kinase pathway modulates the expression of two cellulase genes in Cochliobolus heterostrophus during plant infection. Plant Cell 15:835-844.

Li, W., Wang, B., Wu, J., Lu, G., Hu, Y., Zhang, X., Zhang, Z., Zhao, Q., Feng, Q., Zhang, H., Wang, Z., Wang, G., Han, B., Wang, Z., and Zhou, B. 2009. The Magnaporthe oryzae avirulence gene AvrPiz-t encodes a predicted secreted protein that triggers the immunity in rice mediated by the blast resistance gene Piz-t. Mol. Plant-Microbe Interact. 22:411420.

Lu, C., Tej, S. S., Luo, S., Haudenschild, C. D., Meyers, B. C., and Green, P. J. 2005. Elucidation of the small RNA component of the transcriptome. Science 309:1567-1569.

Madhani, H. D., Galitski, T., Lander, E. S., and Fink, G. R. 1999. Effectors of a developmental mitogen-activated protein kinase cascade revealed by expression signatures of signaling mutants. Proc. Natl. Acad. Sci. U.S.A. 96:12530-12535.

Martinez, J. P., Ottum, S. A., Ali, S., Francl, L. J., and Ciuffetti, L. M. 2001. Characterization of the ToxB gene from Pyrenophora triticirepentis. Mol. Plant-Microbe Interact. 14:675-677.

Matsumura, H., Reich, S., Ito, A., Saitoh, H., Kamoun, S., Winter, P., Kahl, G., Reuter, M., Kruger, D. H., and Terauchi, R. 2003. Gene expression analysis of plant host-pathogen interactions by SuperSAGE. Proc. Natl. Acad. Sci. U.S.A. 100:15718-15723.

Mattinen, L., Tshuikina, M., Mae, A., and Pirhonen, M. 2004. Identification and characterization of Nip, necrosis-inducing virulence protein of Erwinia carotovora subsp. carotovora. Mol. Plant-Microbe Interact. 17:1366-1375.

Mentlak, T. A., Kombrink, A., Shinya, T., Ryder, L. S., Otomo, I., Saitoh, H., Terauchi, R., Nishizawa, Y., Shibuya, N., Thomma, B. P., and Talbot N. J., 2012. Effector-mediated suppression of chitin-triggered immunity by Magnaporthe oryzae is necessary for rice blast disease. Plant Cell 24:322-335.

Meyers, B. C., Tej, S. S., Vu, T. H., Haudenschild, C. D., Agrawal, V., Edberg, S. B., Ghazal, H., and Decola, S. 2004. The use of MPSS for whole-genome transcriptional analysis in Arabidopsis. Genome Res. 14:1641-1653.

Mindrinos, M., Katagiri, F., Yu, G. L., and Ausubel, F. M. 1994. The A. thaliana disease resistance gene RPS2 encodes a protein containing a nucleotide-binding site and leucine-rich repeats. Cell 78:1089-1099.

Mosquera, G., Giraldo, M. C., Khang, C. H., Coughlan, S., and Valent, B. 2009. Interaction transcriptome analysis identifies Magnaporthe oryzae BAS1-4 as biotrophy-associated secreted proteins in rice blast disease. Plant Cell 21:1273-1290.

Munkvold, K. R., and Martin, G. B. 2009. Advances in experimental methods for the elucidation of Pseudomonas syringae effector function with a focus on AvrPtoB. Mol. Plant Pathol. 10:777-793.

Nobuta, K., Venu, R. C., Lu, C., Beló, A., Vemaraju, K., Kulkarni, K., Wang, W., Pillay, M., Green, P. J., Wang, G-L., and Meyers, B. C. 2007. An expression atlas of rice mRNAs and small RNAs. Nat. Biotechnol. 25:473-477.

Odell, J. T., Nagy, F., and Chua, N. H. 1985. Identification of DNA sequences required for activity of the Cauliflower mosaic virus $35 \mathrm{~S}$ promoter. Nature 313:810-812.

Okuyama, Y., Kanzaki, H., Abe, A., Yoshida, K., Tamiru, M., Saitoh, H., Fujibe, T., Matsumura, H., Shenton, M., Galam, D. C., Undan, J., Ito, A., Sone, T., and Terauchi, R. 2011. A multifaceted genomics approach allows the isolation of the rice Pia-blast resistance gene consisting of two adjacent NBS-LRR protein genes. Plant J. 66:467-479.

Orbach, M. J., Farrall, L., Sweigard, J. A., Chumley, F. G., and Valent, B. 2000. A telomeric avirulence gene determines efficacy for the rice blast resistance gene Pi-ta. Plant Cell 12:2019-2032.

Ottmann, C., Luberacki, B., Küfner, I., Koch, W., Brunner, F., Weyand, M., Mattinen, L., Pirhonen, M., Anderluh, G., Seitz, H. U., Nurnberger, 
T., and Oecking, C. 2009. A common toxin fold mediates microbial attack and plant defense. Proc. Natl. Acad. Sci. U.S.A. 106:1035910364.

Panstruga, R, and Dodds, P. N. 2009. Terrific protein traffic: The mystery of effector protein delivery by filamentous plant pathogens. Science 324:748-750.

Qu, S., Liu, G., Zhou, B., Bellizzi, M., Zeng, L., Dai, L., Han, B., and Wang, G-L. 2006. The broad-spectrum blast resistance gene Pi9 encodes a nucleotide-binding site-leucine-rich repeat protein and is a member of a multigene family in rice. Genetics 172:1901-1914.

Qutob, D., Kemmerling, B., Brunner, F., Küfner, I., Engelhardt, S., Gust, A. A., Luberacki, B., Seitz, H. U,, Stahl, D., Rauhut, T., Glawischnig, E., Schween, G., Lacombe, B., Watanabe, N., Lam, E., Schlichting, R., Scheel, D., Nau, K., Dodt, G., Hubert, D., Gijzen, M., and Nürnberger, T. 2006. Phytotoxicity and innate immune responses induced by Nep1like proteins. Plant Cell 18:3721-3744.

Rauyaree, P., Choi, W., Fang, E., Blackmon, B., and Dean, R. A. 2001. Genes expressed during early stages of rice infection with the rice blast fungus Magnaporthe grisea. Mol. Plant Pathol. 2:347-354.

Rehmany, A. P., Gordon, A., Rose, L. E., Allen, R. L., Armstrong, M. R., Whisson, S. C., Kamoun, S., Tyler, B. M., Birch, P. R., and Beynon, J. L. 2005. Differential recognition of highly divergent downy mildew avirulence gene alleles by RPP1 resistance genes from two Arabidopsis lines. Plant Cell 17:1839-1850.

Rep, M. 2005. Small proteins of plant-pathogenic fungi secreted during host colonization. FEMS (Fed. Eur. Microbiol. Soc.) Lett. 253:19-27.

Roberts, C. J., Nelson, B., Marton, M. J., Stoughton, R., Meyer, M. R., Bennett, H. A., He, Y. D., Dai, H., Walker, W. L., Hughes, T. R., Tyres, M., Boone, C., and Friend, S. H. 2000. Signaling and circuitry of multiple MAPK pathways revealed by a matrix of global gene expression profiles. Science 287:873-880.

Saitoh, H., Fujisawa, S., Mitsuoka, C., Ito, A., Hirabuchi, A., Ikeda, K., Irieda, H., Yoshino, K., Yoshida, K., Matsumura, H., Tosa, Y., Win, J., Kamoun, S., Takano, Y., and Terauchi, R., 2012. Large-scale gene disruption in Magnaporthe oryzae identifies MC69, a secreted protein required for infection by monocot and dicot fungal pathogens. PLoS Pathog. 8:e1002711. Published online.

Sheen, J. 2001. Signal transduction in maize and Arabidopsis mesophyll protoplasts. Plant Physiol. 127:1466-1475.

Soanes, D. M., Alam, I., Cornell, M., Wong, H. M., Hedeler, C., Paton, N. W., Rattray, M., Hubbard, S. J., Oliver, S. G., and Talbot, N. J. 2008. Comparative genome analysis of filamentous fungi reveals gene gamily expansions associated with fungal pathogenesis. PLoS ONE 3:e2300. doi:10.1371/journal.pone.0002300. Published online. Published online.

Sweigard, J. A., Carroll, A. M., Kang, S., Farrall, L., Chumley, F. G., and Valent, B. 1995. Identification, cloning, and characterization of PWL2, a gene for host species specificity in the rice blast fungus. Plant Cell 7:1221-1233.

Talbot, N. J. 2003. On the trail of a cereal killer: Exploring the biology of Magnaporthe grisea. Annu. Rev. Microbiol. 57:177-202.

Talbot, N. J., Ebbole, D. J., and Hamer, J. E. 1993. Identification and characterization of MPG1, a gene involved in pathogenicity from the rice blast fungus Magnaporthe grisea. Plant Cell 5:1575-1590.

Tyler, B. M., Tripathy, S., Zhang, X., Dehal, P., Jiang, R. H., Aerts, A., Arredondo, F. D., Baxter, L., Bensasson, D., Beynon, J. L., Chapman, J., Damasceno, C. M., Dorrance, A. E., Dou, D., Dickerman, A. W., Dubchak, I. L., Garbelotto, M., Gijzen, M., Gordon, S. G., Govers, F.,
Grunwald, N. J., Huang, W., Ivors, K. L., Jones, R. W., Kamoun, S. Krampis, K., Lamour, K. H., Lee, M. K., McDonald, W. H., Medina, M., Meijer, H. J., Nordberg, E. K., Maclean, D. J., Ospina-Giraldo, M. D., Morris, P. F., Phuntumart, V., Putnam, N. H., Rash, S., Rose, J. K., Sakihama, Y., Salamov, A. A., Savidor, A., Scheuring, C. F., Smith, B. M., Sobral, B. W., Terry, A., Torto-Alalibo, T. A., Win, J., Xu, Z., Zhang, H., Grigoriev, I. V., Rokhsar, D. S., and Boore, J. L. 2006. Phytophthora genome sequences uncover evolutionary origins and mechanisms of pathogenesis. Science 313:1261-1266.

Venu, R. C., Jia, Y., Gowda, M., Jia, M. H., Jantasuriyarat, C., Stahlberg, E., Li, H., Rhineheart, A., Boddhireddy, P., Singh, P., Rutger, N. Kudrna, D., Wing, R., Nelson, J. C., and Wang, G-L. 2007. RL-SAGE and microarray analysis of the rice transcriptome after Rhizoctonia solani infection. Mol. Genet. Genomics 278:421-431.

Venu, R. C., Sheshu Madhav, M., Sreerekha, M. V., Nobuta, K., Zhang, Y., Carswell, P., Boehm, M. J., Meyers, B. C., Korth, K. L., and Wang, G. L. 2010. Deep and comparative transcriptome analysis of rice plants infested by the beet armyworm (Spodoptera exigua) and water weevil (Lissorhoptrus oryzophilus). Rice 3:22-35.

Venu, R. C., Zhang, Y., Weaver, B., Carswell, P., Mitchell, T. K., Meyers, B. C., Boehm, M. J., and Wang, G-L. 2011a. Large scale identification of genes involved in plant-fungal interactions using Illumina's sequencing-by-synthesis technology. Method Mol. Biol. 722:167-178.

Venu, R. C., Sreerekha, M., Nobuta, K., Beló, A., Ning, Y., An, G., Meyers, B. C., and Wang, G.-L. 2011b. Deep sequencing reveals the complex and coordinated transcriptional regulation of genes related to grain quality in rice cultivars. BMC Genomics 12:190. doi:10.1186/14712164-12-190. Published online.

Watanabe, N., and Lam, E. 2009. Bax inhibitor-1, a conserved cell death suppressor, is a key molecular switch downstream from a variety of biotic and abiotic stress signals in plants. Int. J. Mol. Sci. 10:3149-3167.

Whisson, S. C., Boevink, P. C., Moleleki, L., Avrova, A. O., Morales, J. G., Gilroy, E. M., Armstrong, M. R., Grouffaud, S., van West, P., Chapman, S. Hein, I., Toth, I. K., Pritchard, L., and Birch, P. R. 2007. A translocation signal for delivery of oomycete effector proteins into host plant cells. Nature 450:115-118.

Yoshida, K., Saitoh, H., Fujisawa, S., Kanzaki, H., Matsumura, H., Yoshida, K., Tosa, Y., Chuma, I., Takano, Y., Win, J., Kamoun, S., and Terauchi, R. 2009. Association genetics reveals three novel avirulence genes from the rice blast fungal pathogen Magnaporthe oryzae. Plant Cell 21:1573-1591.

Zhang, J., and Zhou, J. M. 2010. Plant immunity triggered by microbial molecular signatures. Mol. Plant 3:783-93.

\section{AUTHOR-RECOMMENDED INTERNET RESOURCES}

Arabidopsis MPSS Plus database: mpss.udel.edu/\#rice

Broad Institute (version 6.0) download sequence webpage: www.broadinstitute.org/annotation/genome/magnaporthe_grisea/Multi Downloads.html

Illumina website: www.illumina.com

Magnaporthe oryzae community annotation database: www.mgosdb.org

Michigan State University's Plant Biology directory: ftp.plantbiology.msu.edu/pub/data/Eukaryotic_Projects/o_sativa/annotat ion dbs/pseudomolecules/version 6.0

SAGEspy program: www.osc.edu/research/bioinformatics/projects/sagespy/index.shtml 